\title{
Neurofibroma of the cervical spine in infants: a case-based update
}

\author{
Ajay Sinha ${ }^{1} \cdot$ Benedetta Pettorini $^{1}$
}

Received: 6 October 2016/Accepted: 7 October 2016 / Published online: 20 October 2016

(C) Springer-Verlag Berlin Heidelberg 2016

Reply to comment:

We read the comments of Mr. Lavrador with great interest.

He shares his experience of managing an infant with high cervical neurofibroma.

The significant difference between the two cases is the size of the intradural component of the tumour. In our patient, the intradural tumour was the predominant component causing significant cord compression and we had significant concerns with regard to her respiration and lower cranial nerve function.

Pre-operatively, our patient was showing initial signs of respiratory distress and swallowing function disorders.
We felt in view of the severe cord compression that radical decompression of the intradural component of the tumour was warranted. The extraspinal component of the tumour was left behind and will be monitored long term.

In addition, there were no red flags for a diagnosis of NF1 pre-operatively and we felt a histopathological diagnosis via open surgery biopsy was mandatory.

We did perform a laminoplasty to avoid long-term neck deformity which unfortunately did set in but luckily at the moment is under control.

Our case represents a rather unusual first presentation of NF1 with significant spinal cord compression and hence the report.

Compliance with ethical standards

Conflict of interest The authors report no conflict of interest.
Benedetta Pettorini

benedetta.pettorini@alderhey.nhs.uk

1 Paediatric Neurosurgery Department, Alder Hey Children's Hospital NHS Foundation Trust, Eaton Road, Liverpool L122AP, UK 